\title{
O SIGNIFICADO DE DIREITOS FUNDAMENTAIS SOB UM ASPECTO ESTRUTURAL QUADRINUCLEAR
}

\author{
Maicon Melito de Souza
}

ISSUE DOI: $10.21207 / 1983.4225 .270$

\section{RESUMO}

O objetivo deste trabalho é esclarecer o significado de direitos fundamentais sob um aspecto estrutural de quatro núcleos. Os núcleos componentes da estrutura dos direitos fundamentais são: suas fontes, a conceituação de suas essências, suas matérias e as eficácias. A análise das fontes permite verificar as fontes formais e materiais dos direitos humanos e fundamentais. Com a conceituação, distinguimos as acepções entre direitos humanos e direitos fundamentais. No terceiro núcleo, é delimitada a classificação material desses direitos. Já no último núcleo, há uma reflexão sobre a problemática da eficácia das normas fundamentais.

Palavras-chave: Direitos Humanos. Direitos Fundamentais. Aspecto Estrutural Quadrinuclear.

\section{INTRODUÇÃO}


É praticamente certo que em todas as sociedades existam normas fundamentais para a sustentação de seus ordenamentos. Com status de regras máximas, as mesmas têm a pretensão de organizar os indivíduos.

Transformadas ao longo dos tempos, tais normas incorporaram as mais variadas matérias, de acordo com as influências exercidas pelos sistemas políticos e ideológicos então vigentes. Com efeito, os direitos subjetivos da pessoa humana ganharam inúmeros sentidos, sendo as acepções diferentes no tempo e espaço.

Nesses termos, para a definição do significado de direitos fundamentais deve-se buscar a compreensão real e pedagógica da essência desses direitos, através do estudo estruturado dos núcleos que compõem as normas jurídicas como um todo. Só assim, poderá ser transmitido o conhecimento que deve ser de todos.

\section{ASPECTO ESTRUTURAL QUADRINUCLEAR}

A enorme dificuldade de professores, doutrinadores e pesquisadores para explicar o verdadeiro significado de direitos fundamentais é notória, sendo ainda maior para leigos em direito. $\mathrm{O}$ aspecto estrutural quadrinuclear dos direitos fundamentais tem como escopo esclarecê-los de forma eficaz.

A análise de uma norma jurídica nos permite verificar a existência de quatro núcleos específicos para a sua composição total, são eles: as fontes de origem da norma, o conceito ou pretensão da norma, a materialidade disciplinadora e a eficácia da pretensão normativa.

Através de um método de explicação estruturado nesses quatro núcleos, daí a expressão "aspecto estrutural quadrinuclear", é possível elucidar de forma precisa e crítica o significado de direitos fundamentais, que também são normas jurídicas.

\section{FONTES DOS DIREITOS FUNDAMENTAIS}

Sabendo que as fontes do direito são os fatos que influenciam a origem de determinada norma jurídica, o conhecimento das fontes formais 
e materiais dos direitos fundamentais nos proporcionará o entendimento do motivo da criação desses direitos.

As fontes materiais dos direitos fundamentais são os fatores sociais que baseiam a essência das normas sociais. ${ }^{1}$ Por sua vez, esses fatores são baseados em valores consagrados pelos vários indivíduos do determinado Grupo e/ou pelas autoridades exercidas no mesmo.

Com o mundo cada vez mais interligado, os costumes dos determinados grupos sociais foram sofrendo mutações em razão das mais variadas relações culturais, dando ensejo ao entendimento de direitos naturais a todos. $\mathrm{O}$ direito passou a ser visto não apenas como mero instrumento de controle de conduta, mas também como instrumento normativo para a proteção do bem-estar das pessoas, surgindo a percepção de direitos garantidores da dignidade humana.

Os direitos humanos passaram, e ainda passam, por mutações periodicamente, porém, as mutações são complementativas, decorrentes da progressiva cumulação de valores pelas sociedades, não havendo alternância, e sim aprimoramento de direitos. ${ }^{2}$ A teorização geracional ou dimensional dos direitos humanos prova isso. Resguardada as peculiaridades de cada teórico, as três dimensões dos direitos humanos, ou pelo menos as consideradas três primeiras, auxiliam a exposição das fontes materiais dos direitos fundamentais.

Na primeira dimensão dos direitos humanos, é caracterizado o ideal liberal da classe burguesa nas revoluções do século XVIII. A alta persuasão econômica da burguesia, principalmente a europeia e a americana, com a busca da não intervenção estatal na área econômica, de proteção à propriedade privada, de garantias processuais e de igualdade puramente formal perante a lei, foi a primeira grande fonte material dos direitos fundamentais.

Nos direitos de segunda dimensão, as fontes materiais foram os anseios de soluções das mazelas causadas pelo vertiginoso processo de industrialização e mercantilização global, que afetou de forma incisiva as classes economicamente baixas. A massificação dos meios industriais, a aplicação de métodos de produção degradantes e os abusos no expediente

\footnotetext{
1 MONTORO, André Franco. 1916-1999. Introdução à ciência do direito 28. ed. rev. e atual. - São Paulo: Editora Revista dos Tribunais, 2009. p. 377.

2 BONAVIDES, Paulo. Curso de Direito Constitucional. 9. ed. rev. atual. ampliada. (em apêndice texto da Constituição Federal de 1988, com a EC até a de n. 24, de 10.12.1999). São Paulo-SP: Malheiros, 2000. p. 517.
} 
trabalhista deram causa aos anseios daquela nova classe operária. Reivindicavam direitos trabalhistas e direitos de assistência social por parte do Estado, saúde, educação e segurança. O período fica marcado pela busca da igualdade material.

Já na terceira dimensão dos direitos humanos, as fontes materiais resultaram das atrocidades vividas pela espécie humana no século XX. As barbáries causadas pela Segunda Guerra Mundial motivaram a busca da fraternidade como norma. A paz entre pessoas e povos passou a ser pretensão de direito, bem como a autodeterminação dos povos e o respeito cultural, os direitos coletivos.

No que diz respeito às fontes formais ${ }^{3}$, dispositivos jurídicos fundamentadores da norma e de atribuição de caráter de direito positivo, os direitos fundamentais tiveram várias fontes ao longo das gerações.

A Magna Carta, de 1215, Inglaterra, é a legislação considerada pela doutrina dominante como pioneira do que viria a ser o constitucionalismo, em razão de seu impacto histórico e social. Os burgueses exigiam a declaração formalizada de seus direitos e a limitação do poder do rei, João Sem-Terra, que acabou cedendo. Posteriormente, outro marco importante para a formalização dos direitos humanos de liberdade foi criado: o Habeas Corpus Act, de 1679, Inglaterra. O instituto veio sanar as imperfeições existentes, criando uma ação judicial própria para a defesa da liberdade cerceada arbitrariamente por autoridade. Entretanto, não tinha sido o bastante, em 1689, o parlamento britânico aprovou, e posteriormente foi promulgada com força de lei a declaração dos direitos e liberdades das pessoas, bem como a independência das eleições dos membros do parlamento e a imunidade parlamentar material, declaração conhecida como Bill of Rights inglês. ${ }^{4}$

Em relação ao continente americano, foi em 1776, com a Declaração de Direitos da Virgínia que o constitucionalismo se iniciou. Tendo a finalidade de positivar os direitos de liberdade e igualdade formal dos homens, é considerada a primeira constituição moderna, porque já estabelecia os princípios a serem seguidos no Estado. Porém, o mecanismo constitucional continuou, não mais de forma específica de cada Estado confederado, e sim sob o princípio do pacto federativo. A Constituição dos Estados Unidos, de 1787, transformou a Confederação em Federação, entretanto, não

\footnotetext{
${ }^{3}$ MONTORO, André Franco. op. cit., loc. cit., nota 1.

4 DALlARI, Dalmo de Abreu, 1931 - Elementos de Teoria Geral do Estado - 20. ed. atual. - São Paulo: Saraiva, 1998. p. 168.
} 
detalhava os direitos dos cidadãos. A Carta dos Direitos dos Estados Unidos, Bill of Rights americano, foi ratificada somente em 1791.

É sempre pertinente lembrar que esses diplomas legais ingleses e estadunidenses declaravam como norma o direito de igualdade entre os seus cidadãos, igualdade apenas formal, o que é condizente apenas sob a lógica liberal de prestação negativa da primeira dimensão dos direitos humanos e fundamentais.

A França caminhou em passos semelhantes: a instalação da Assembleia Nacional Constituinte francesa, em 1789, ano da Revolução, originou a Declaração dos Direitos do Homem e do Cidadão, na qual a peculiaridade era a generalização dos direitos, reconhecendo e propagando a ideia de que esses direitos também eram inerentes a outros povos. A Constituição Francesa de 1791, aprovada pela Assembleia Nacional Constituinte, seguiu os mesmo ideais, todavia, sendo paradoxal ao adotar o sufrágio censitário. Já a nova Constituição, de 1793, embora influenciada pela Declaração de 1789, era mais radical. Com apelos sociais, era possível ver naquela Constituição os sinais de direitos sociais, característicos da segunda dimensão dos direitos humanos, a disposição sobre o dever da sociedade em garantir a subsistência dos indivíduos em condições de miséria foi exemplo claro. Mas em razão da crise social, das guerras travadas pela França e do governo provisório, conhecido como Terror, a Constituição praticamente não vigorou. Em 1795, foi promulgada outra Constituição, de cunho liberal, que teve como objetivo afastar os diferentes ideais dos antigos regimes, não observando as várias prerrogativas sociais anteriormente conquistadas, verdadeiro retrocesso.

Na segunda dimensão dos direitos fundamentais, a Constituição dos Estados Unidos Mexicanos, de 1917, foi um dos marcos. Originou-se de movimentos revolucionários no México, que reivindicavam direitos assistenciais, trabalhistas, previdenciários e de reforma agrária. Sua característica diferencial foi o lançamento das bases do Estado Social de Direito.

A Constituição do Império Alemão, de 1919, conhecida como Constituição de Weimar, seguiu no mesmo sentido da Constituição Mexicana. A difícil situação social alemã, decorrente da Primeira Guerra Mundial, inspirou a elaboração dos direitos e deveres fundamentais dos alemães. A Constituição de 1919 fundamentou um grande rol de direitos sociais, com destaque para a reforma agrária, a função social da propriedade, a proteção dos direitos trabalhistas e previdenciários e até a ordem econômica. 
Mesmo assim, os direitos de segunda dimensão nos diplomas mexicano e alemão ainda não disciplinavam de modo necessário as questões de igualdade de gênero. A equiparação étnica e racial era meramente formal. A igualdade material envolvia apenas questões masculinas e de subsistência humana, a manutenção do termo direitos dos homens na sociedade, como também, a vigência dos Estados colonizadores foram tristes exemplos.

Por último, como principal fonte formal dos direitos fundamentais de terceira dimensão foi promulgada pela Organização das Nações Unidas - ONU - em 1948 a Declaração Universal dos Direitos Humanos, objetivando reconhecer a necessidade de proteção dos direitos dos povos e também influenciar a fundamentalização dos direitos humanos nas Constituições dos Estados. Tratou das problematizações raciais, étnicas, de gênero - no seu sentido mais estrito - e do ordenamento pacífico e fraterno através dos direitos difusos.

\section{CONCEITUAÇÃO DE DIREITOS FUNDAMENTAIS}

As diferentes concepções de direito entre direito natural e direito positivo serviram para denominar o que posteriormente seria chamado de direitos fundamentais.

$\mathrm{Na}$ filosofia jusnaturalista, os direitos naturais são as condições essenciais para a subsistência física e moral do indivíduo, nascendo espontaneamente com o ser humano, inerentes ao estado humano, não podendo ser mudados já que foram originados do poder transcendente. No positivismo, o direito positivo nada mais é do que normas criadas pelos seres humanos, derivadas da razão humana, com a finalidade de ordenar a vida em sociedade. A utilização da expressão direitos naturais ou outras derivadas do mesmo pensamento usadas pelos contratualistas foi rejeitada pelos positivistas. Esses utilizavam outros termos relacionados às suas ideias ao longo das gerações: direitos individuais, liberdades individuais liberdades públicas. ${ }^{5}$ Resultado de todo esse processo é a atual definição jurídica de direitos humanos, direitos inerentes à preservação do estado de dignidade

5 SAMPAIO, José Adércio Leite. Direitos Fundamentais: Retórica e Historicidade Belo Horizonte: Del Rey, 2004. p. 8. 
humana, válidos para todos os seres humanos, declarados no plano internacional dos povos, independentes do reconhecimento na ordem interna Estatal.

A necessidade de efetividade dos direitos humanos proporcionou seus reconhecimentos no âmbito interno dos Estados, sendo primeiramente estruturados pela doutrina germânica, denominados na Alemanha pela expressão Grundrechte. A prática se deu na sistemática fundamentação dos direitos subjetivos públicos na Constituição de Weimar, a qual positiva especificadamente os direitos anteriormente reconhecidos como apenas de fato. ${ }^{6}$ Com efeito, os direitos humanos positivados passaram a ser denominados direitos fundamentais, quando fundamentados no sistema legal interno dos Estados.

Os direitos fundamentais são os direitos humanos expressos ou implicitamente reconhecidos no ordenamento constitucional de determinado Estado. ${ }^{7}$ Costumam disciplinar mais precisamente as pretensões valoradas pelos direitos humanos, delimitados material e funcionalmente, visto que são institucionalmente garantidos pelo direito positivo. ${ }^{8}$ Positivados em Constituição, costumam ser regulamentados em normas infraconstitucionais.

Porém, devemos observar a possibilidade de direitos serem denominados fundamentais quando de fato não são, sendo formalizados como fundamentais no campo jurídico, embora materialmente não carreguem a mesma importância, como poderá ser percebido nos próximos títulos deste artigo.

\section{CLASSIFICAÇÃO MATERIAL DOS DIREITOS FUNDAMENTAIS}

Antes de começar a classificação material dos direitos fundamentais é pertinente distinguir uma classificação funcional dos direitos e ga-

\footnotetext{
${ }^{6}$ MIRANDA, Jorge. Manual de Direito Constitucional, Tomo IV, Direitos Fundamentáis. $3^{\mathrm{a}}$ ed., rev. atual. - [s.1.], Coimbra Editora, 2000. p. 7.

${ }^{7}$ VIEIRA, Oscar Vilhena. Direitos Fundamentais: Uma Leitura da Jurisprudência do STF. colaboração de Flávia Scabin. - São Paulo-SP, Malheiros Editores Ltda, 2006. p. 36. 8 LUÑO, Antonio-Enrique Pérez. Los Derechos Fundamentales. $6^{\mathrm{a}}$ ed., Madrid: Ed. Tecnos, 1995. p. 46-47.
} 
rantias fundamentais. Podemos dizer com segurança que direitos fundamentais definem os direitos subjetivos, enquanto as garantias fundamentais são as normas assecuratórias dos direitos fundamentais, assegurando a manutenção das prestações previstas nos primeiros. ${ }^{9}$

Com o passar dos períodos dimensionais dos direitos humanos, o rol de direitos fundamentais cresce quase que na mesma proporção. Assim surge a dificuldade de classificá-los materialmente, impedindo que os intérpretes e destinatários das normas fundamentais as entendam.

O modo como são reconhecidos nos diversos Estados influencia muito a classificação. Nunca houve uniformidade material universalmente considerada, visto as diferenças sociais e jurídicas de vários países, distinguindo formalmente as normas materialmente iguais. Percebe-se que a classificação material dos direitos fundamentais depende da comparação com os direitos humanos, pois os primeiros são de caráter interno e os segundos de caráter universal. As dimensões são classificadas pela similaridade material dos direitos humanos fundamentados, dando resultado a uma compreensão melhor solidificada do campo material dos direitos fundamentais. Frequentemente adotada pela melhor doutrina, é aperfeiçoada constantemente.

A utilização da Constituição Brasileira, de 1988, como fonte para a demonstração dos direitos das diferentes dimensões, é absolutamente pertinente, pois esse diploma consegue abarcar todas as três dimensões já consagradas. Assim, analisemos as matérias dos direitos fundamentais.

Como já mencionado, a primeira dimensão dos direitos fundamentais foi a dos direitos individuais frente ao Estado, de defesa perante a intervenção estatal na vida individual, reconhecidos como direitos de prestação negativa, em razão da pretensão de abstenção da conduta comissiva do Estado. Os direitos à liberdade, à propriedade e à igualdade formal são, sem dúvida, os maiores exemplos dessa dimensão. A Constituição Brasileira os reconhece logo no início:

Art. 5. ${ }^{\circ}$ Todos são iguais perante a lei, sem distinção de qualquer natureza, garantindo-se aos brasileiros e aos estrangeiros residentes no País a inviolabilidade

\footnotetext{
9 SILVA, José Afonso da. Curso de Direito Constitucional Positivo. 30. ed. rev. e atual. (até a Emenda Constitucional n. 56, de 20.12.2007) - São Paulo, Malheiros Editores, 2008. p. 412.
} 
do direito à vida, à liberdade, à igualdade, à segurança e à propriedade, nos termos seguintes:

I - homens e mulheres são iguais em direitos e obrigações, nos termos desta Constituição;

II - ninguém será obrigado a fazer ou deixar de fazer alguma coisa senão em virtude de lei;

IV - é livre a manifestação do pensamento, sendo vedado o anonimato;

VI - é inviolável a liberdade de consciência e de crença, sendo assegurado o livre exercício dos cultos religiosos e garantida, na forma da lei, a proteção aos locais de culto e a suas liturgias;

$\mathrm{X}$ - são invioláveis a intimidade, a vida privada, a honra e a imagem das pessoas, assegurado o direito a indenização pelo dano material ou moral decorrente de sua violação;

XI - a casa é asilo inviolável do indivíduo, ninguém nela podendo penetrar sem consentimento do morador, salvo em caso de flagrante delito ou desastre, ou para prestar socorro, ou durante o dia, por determinação judicial;

$\mathrm{XV}$ - é livre a locomoção no território nacional em tempo de paz, podendo qualquer pessoa, nos termos da lei, nele entrar, permanecer ou dele sair com seus bens;

XVI - todos podem reunir-se pacificamente, sem armas, em locais abertos ao público, independentemente de autorização, desde que não frustrem outra reunião anteriormente convocada para o mesmo local, sendo apenas exigido prévio aviso à autoridade competente.

Na segunda dimensão, a fundamentalização se dá nos direitos econômicos, sociais e culturais. É atribuído ao Estado comportamento ativo na realização das pretensões sociais. As prestações estatais são positivas, pois é exigida do Poder Público a participação no estabelecimento do bem-estar social, como educação, saúde, trabalho, ordem econômica, entre outras. ${ }^{10}$ Estão previstos na Constituição nos seguintes artigos:

10 SARLET, Ingo Wolfgang. A Eficácia dos Direitos Fundamentais. 2 ed. rev. atual. e ampl. - Porto Alegre: Livraria do Advogado, 2001. p. 51. 
Art. 6. São direitos sociais a educação, a saúde, a alimentação, o trabalho, a moradia, o lazer, a segurança, a previdência social, a proteção à maternidade e à infância, a assistência aos desamparados, na forma desta Constituição.

Art. 7. ${ }^{\circ}$ São direitos dos trabalhadores urbanos e rurais, além de outros que visem à melhoria de sua condição social:

II - seguro-desemprego, em caso de desemprego involuntário;

III - fundo de garantia do tempo de serviço.

Art. 174. Como agente normativo e regulador da atividade econômica, o Estado exercerá, na forma da lei, as funções de fiscalização, incentivo e planejamento, sendo este determinante para o setor público e indicativo para o setor privado.

Art. 194. A seguridade social compreende um conjunto integrado de ações de iniciativa dos Poderes Públicos e da sociedade, destinadas a assegurar os direitos relativos à saúde, à previdência e à assistência social.

Art. 205. A educação, direito de todos e dever do Estado e da família, será promovida e incentivada com a colaboração da sociedade, visando ao pleno desenvolvimento da pessoa, seu preparo para o exercício da cidadania e sua qualificação para o trabalho.

Já os direitos fundamentais de terceira dimensão desprendem do ser humano individualmente considerado como seu titular único. Seus titulares são grupos humanos, a coletividade humana em geral, resultando nas suas características de titularidade coletiva ou difusa.11 Reconhecidos como direitos de fraternidade e solidariedade, são direitos à paz, à proteção e equilíbrio do meio ambiente, à conservação e utilização do patrimônio

11 SARLET, Ingo Wolfgang. A Eficácia dos Direitos Fundamentais. 2 ed. rev. atual. e ampl. - Porto Alegre: Livraria do Advogado, 2001. p. 51. 
histórico e cultural, à autodeterminação dos povos. Exemplos desses direitos na Constituição:

Art. 3. ${ }^{\circ}$ Constituem objetivos fundamentais da República Federativa do Brasil:

I - construir uma sociedade livre, justa e solidária.

Art. 4. ${ }^{\circ}$ A República Federativa do Brasil rege-se nas suas relações internacionais pelos seguintes princípios:

I - independência nacional;

II - prevalência dos direitos humanos;

III - autodeterminação dos povos;

IV - não intervenção;

$\mathrm{V}$ - igualdade entre os Estados;

VI - defesa da paz;

VII - solução pacífica dos conflitos;

VIII - repúdio ao terrorismo e ao racismo;

IX - cooperação entre os povos para o progresso da humanidade;

$\mathrm{X}$ - concessão de asilo político.

Parágrafo único. A República Federativa do Brasil buscará a integração econômica, política, social e cultural dos povos da América Latina, visando à formação de uma comunidade latino-americana de nações.

Art. 225. Todos têm direito ao meio ambiente ecologicamente equilibrado, bem de uso comum do povo e essencial à sadia qualidade de vida, impondo-se ao poder Púbico e à coletividade o dever de defendê-lo e preservá-lo para as presentes e futuras gerações.

Por fim, o motivo de se averiguar somente as três dimensões supramencionadas é que, embora seja possível observar a formação de novos direitos inerentes à preservação do estado de dignidade humana valorados pelo próprio significado universal de dignidade humana no decorrer dos tempos, esses ainda não são positivados na imensa maioria dos casos. São 
direitos humanos, mas por enquanto não são fundamentais, no sentido jurídico da palavra, evidentemente. 12 Consequentemente, a classificação material foi baseada na premissa dos direitos fundamentais como direitos humanos positivados no âmbito interno do Estado, não sendo pretendida a classificação dos direitos fundamentais que não fossem de fato - ditos como fundamentais pela formalização jurídica, mas vazios de materialidade de direitos humanos.

\section{PROBLEMÁTICA DA EFICÁCIA DOS DIREITOS FUNDAMENTAIS}

A eficácia dos direitos fundamentais é realmente complexa, verdadeira problemática. Teorias tentam delimitar o plano da efetividade das normas constitucionais, questões que não foram solucionadas nem mesmo pelo legislador constituinte.

Antes das questões propriamente consideradas de eficácia fundamental, tipicamente de caráter mais instrumental, o conceito de direitos humanos é um dos primeiros problemas enfrentados na busca da efetividade de tais normas. Norberto Bobbio critica a busca de uma definição absoluta de direitos humanos, o que para ele é ilusão. Propõe o Jurista quatro grandes dificuldades para a definição, a saber: a vaga expressão de direitos do homem - a qual podemos entender como direitos humanos -, pois a finalidade de todas as áreas do direito é o ser humano; as definições tautológicas, como "os direitos que cabem ao ser humano enquanto humano"; a pouca efetividade das conceituações propostas, delimitando mais um caminho a ser seguido do que a própria conceituação daqueles direitos; e os termos avaliativos introduzidos nas concepções, porque esses termos podem ser valorados de acordo com a ideologia do interprete; exemplo: "são aqueles cujo reconhecimento é condição necessária para o aperfeiçoamento da pessoa humana". ${ }^{13}$

A concepção de direitos humanos influencia diretamente a concepção de direitos fundamentais. A eficácia de direitos meramente formalizados como fundamentais pode não ser a desejada por seus destinatários,

\footnotetext{
${ }^{12}$ SOUZA, Maicon Melito de. Estrutura dos Direitos Fundamentais. TC. - Franca-SP: Faculdade de Direito de Franca, 2015. p. 35.

${ }^{13}$ BOBBIO, Norberto, 1909 - A Era dos Direitos; apresentação de Celso Lafer. - Nova ed. - Rio de Janeiro: Elsevier, 2004. p. 37.
} 
pois as pretensões fundamentadas pelo legislador podem ser diferentes ou até mesmo antagônicas às pretensões sociais.

Noutro campo problemático, o da exposição da matéria dos direitos fundamentais, que deve ser clara e objetiva, a ocorrência de direitos e princípios fundamentais implícitos no sistema ordenador é uma realidade. Em nossa atual Constituição, há a tentativa de solucionar o problema: Art. $5 .^{\circ}, \S 2 .^{\circ}$ "Os direitos e garantias expressos nesta Constituição não excluem outros decorrentes do regime e dos princípios por ela adotados, ou dos tratados internacionais em que a República Federativa do Brasil seja parte".

Questão que parece ser a solução da efetividade é a disposição constitucional brasileira de aplicação imediata das normas e garantias fundamentais, que assim diz: Art. 5. ${ }^{\circ}, \S 1 .^{\mathrm{o}}$ " As normas definidoras dos direitos e garantias fundamentais têm aplicação imediata". Não obstante, a interpretação constitucional feita pela doutrina dominante nos mostra que a solução ainda não está perto de ocorrer. Usemos de exemplo o que Luiz Roberto Barroso conceituou como normas constitucionais programáticas, as quais traçam fins sociais a serem alcançados pela futura atuação do Estado, não formando para os jurisdicionados a possibilidade de exigir prestações positivas, mas não impedindo a faculdade de demandar do mesmo a abstenção de quaisquer atos de contravenção das diretrizes sociais traçadas por ele, pois gerariam direitos subjetivos somente nas versões de prestações negativas. ${ }^{14}$

Ingo Wolfgang Sarlet explica muito bem o cerne do problema, ao dizer que os direitos de defesa assumem rotineiramente a feição de direitos subjetivos, não existindo grande controvérsia em torno de suas aplicabilidades imediatas, não ocorrendo igualmente com os direitos de prestações positivas. O Autor diz que os direitos de prestação positiva, por exigirem o comportamento comissivo, causam inúmeras dificuldades de aplicação, o que leva muitos não considerá-los de aplicabilidade imediata, provocando o entendimento da eficácia restrita. ${ }^{15}$

Ponto igualmente problemático nos tempos atuais tem sido o conflito de princípios fundamentais, quando os direitos e garantias expressos na Constituição Brasileira não excluem outros princípios por ela adotados, como foi visto no seu $\S 2 .^{\circ}$ do Art. 5. ${ }^{\circ}$. Destarte, com o sopesamento de

\footnotetext{
${ }^{14}$ BARROSO, Luís Roberto. Curso de Direito Constitucional Contemporâneo: os Conceitos Fundamentais e a Construção do Novo - 4. ed. - São Paulo: Saraiva, 2013. p. 225.

${ }^{15}$ SARLET, Ingo Wolfgang. A Eficácia dos Direitos Fundamentais. 2 ed. rev. atual. e ampl. - Porto Alegre: Livraria do Advogado, 2001. p. 238; nota 11.
} 
princípios fundamentais - precedência de um ou mais princípios em face de outros em determinado caso concreto, como dito por Robert Alexy ${ }^{16}$ a efetividade de direitos fundamentais pode ser excepcionalmente cerceada por direito. Os questionamentos dos motivos pelos quais chamamos de "obrigação jurídica" o que o direito diz que deve ser, e se "obrigação" é um mero termo técnico de enunciação da lei ou possui alguma relação com a obrigação moral são levantados por Ronald Dworkin. Ele tenta alertar sobre os riscos de ineficiência das pretensões humanas caso não identificarmos os princípios seguidos por nós. ${ }^{17}$ Dessa forma, para não cairmos em um reducionismo de dignidade humana a precedência principiológica deve ser vinculada à materialidade dos direitos humanos presente no princípio, sendo inadmissível a preponderância de princípios meramente formais, axiologicamente conflitantes àqueles direitos. ${ }^{18}$

É claro que a eficácia plena de todos os direitos humanos fundamentais não está restrita ao que aqui foi explanado, entretanto, o Direito tem sido a maior ferramenta de manutenção do status quo. É exigível o redimensionamento do papel instrumentalizador do jurista e do Poder Judiciário para a essência das verdadeiras pretensões fundamentais da Constituição Brasileira, pois Direito não pode ser entendido apenas como simples racionalidade instrumental, diz nesse sentido Lenio Luiz Streck. ${ }^{19}$

\section{CONCLUSÃO}

Concluindo, a definição do significado de direitos fundamentais, sob o aspecto quadrinuclear, permite a verdadeira compreensão da essência desses direitos. $\mathrm{O}$ estudo estruturado em núcleos - fontes formais e materiais, a conceituação de direitos humanos e direitos fundamentais, a classificação material, a problematização da eficácia dessas normas - possibilita

\footnotetext{
${ }^{16}$ ALEXY, Robert. Teoria dos Direitos FUNDAMENTAIS. Tradução Silva, Virgílio Afonso. São Paulo: Malheiros, 2008. Tradução de Theorie der Grundrechte. 5. ed. [s.1.]: Suhrkamp Verlaz, 2006. p. 91-103.

${ }^{17}$ DWORKIN, Ronald. Levando os Direitos a sério. Tradução e notas Nelson Boeira. Tradução de Talkin rights seriously - São Paulo: Martins Fontes, (Justiça e direito), 2002. p. 23-72.

${ }^{18}$ SOUZA, Maicon Melito de. Estrutura dos Direitos Fundamentais. TC. - Franca-SP: Faculdade de Direito de Franca, 2015. p. 38. nota 15.

${ }^{19}$ STRECK, Lenio Luiz. Jurisdição Constitucional e Hermenêutica: Uma Nova Crítica do Direito - 2. ed. - Rio de Janeiro: Forense, 2004. p. 15.
} 
o aprendizado crítico, redimensionando o estudante da prática instrumentalizadora do status quo para a eficácia real dos direitos humanos.

\section{REFERÊNCIAS BIBLIOGRÁFICAS}

ALEXY, Robert. Teoria dos Direitos Fundamentais. Tradução Silva, Virgílio Afonso. São Paulo: Malheiros, 2008. Tradução de Theorie der Grundrechte. 5. ed. [s.1.]: Suhrkamp Verlaz, 2006.

BARROSO, Luís Roberto. Curso de Direito Constitucional Contemporâneo: os Conceitos Fundamentais e a Construção Do Novo Modelo - 4. ed. - São Paulo: Saraiva, 2013.

BOBBIO, Norberto, 1909 - A Era dos Direitos; tradução de Carlos Nelson Coutinho; apresentação de Celso Lafer. - Nova ed. - Rio de Janeiro: Elsevier, 2004.

BONAVIDES, Paulo. Curso de Direito Constitucional. 9. ed. rev. atual. ampliada. (em apêndice texto da Constituição Federal de 1988, com a EC até a de n. 24, de 10.12.1999). São Paulo-SP: Malheiros, 2000. DALlaRI, Dalmo de Abreu, 1931 - Elementos de Teoria Geral do Estado - 20. ed. atual. - São Paulo: Saraiva, 1998.

DWORKIN, Ronald. Levando os Direitos a Sério; tradução e notas Nelson Boeira. Tradução de Talkin rights seriously - São Paulo: Martins Fontes, (Justiça e direito), 2002.

FERREIRA FILHO, Manoel Gonçalvez. Direitos Humanos Fundamentais. - 12. ed. - São Paulo: Saraiva, 2010.

MIRANDA, Jorge. Manual de Direito Constitucional, Tomo IV, Direitos Fundamentais. $3^{a}$ ed., rev. atual. - [s.1.], Coimbra Editora, 2000.

MONTORO, André Franco. 1916-1999. Introdução à Ciência do Direito. - 28. ed. rev. e atual. - São Paulo: Editora Revista dos Tribunais, 2009.

PÉREZ LUÑO, Antonio-Enrique. Los Derechos Fundamentales. $6^{\mathrm{a}}$ ed., Madrid: Ed. Tecnos, 1995.

SAMPAIO, José Adércio Leite. Direitos fundamentais: Retórica e Historicidade - Belo Horizonte: Del Rey, 2004.

SARLET, Ingo Wolfgang. A Eficácia dos Direitos Fundamentais. 2 ed. rev. atual. e ampl. - Porto Alegre: Livraria do Advogado, 2001. 
SILVA, José Afonso da. Curso de Direito Constitucional Positivo. 30. ed. rev. e atual. (até a EmendaConstitucional n. 56, de 20.12.2007) - São Paulo, Malheiros Editores, 2008.

STRECK, Lenio Luiz. Jurisdição Constitucional e Hermenêutica: uma nova crítica do Direito - 2. ed. - Rio de Janeiro: Forense, 2004.

VIEIRA, Oscar Vilhena. Direitos Fundamentais: Uma Leitura da Jurisprudência do STF. colaboração de Flávia Scabin. - São Paulo-SP, Malheiros Editores Ltda, 2006. 